\title{
Japan seeks targeted science funding ...
}

[TOKYO] Japan's science policy-makers are planning to make a statement of their priorities in science and technology in an attempt to safeguard funding for key research areas in government budgets. The move marks a departure from the government's traditional approach of spreading research grants thinly and evenly, and would help to identify research areas covered by different ministries and agencies.

The content of the statement - based on a recent survey of science-related ministries and agencies - is currently being discussed by the policy committee of the Council for Science and Technology, the principal science policy-making body, which is chaired by the prime minister.

The policy committee aims to define a number of high-priority research fields that would receive a larger share of government research funds. These will probably include information sciences, genome research, and some areas that were not covered by the fiveyear plan for science and technology, which was launched in 1996, to double Japan's science spending to a total of $¥ 17$ trillion (US\$140 billion) by 2001 .

The statement would be incorporated into guidelines on promoting science, and will be compiled by the end of this month, before ministries start drawing up their budget requests for the next fiscal year. According to the council, the statement will be reflected in the 'special promotion' funds in the budget for the fiscal year 2000.

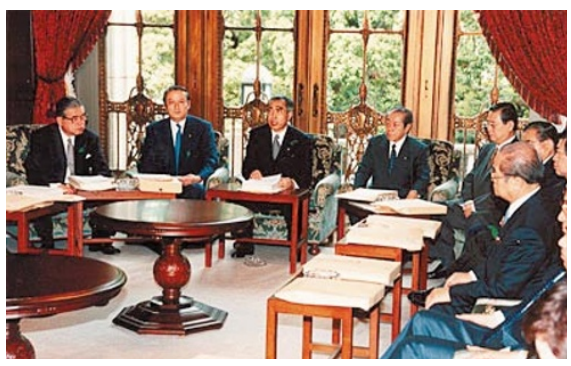

Looking ahead: Japan's administrative reform committee (above) will determine the future organization of science advice.

Japanese researchers have often criticized the government's inability to adequately support high-priority research areas. For example, many blame Japan's poor track record in genome sequencing on the government's failure to tackle genome research on a national level (see Nature 399, 96; 1999). The new plan is intended to distribute research funds more effectively and to explore emerging research areas that need greater support.

According to Nobuhiro Muroya, deputy director of the planning and evaluation division of the Science and Technology Agency (STA), the statement would form an important basis for the second phase of the science and technology basic plan, which begins in April 2001 (see Nature 397, 638; 1999).

But he describes the attempt to specify the priorities in scientific research as "hardly straightforward". He adds: "Unsurprisingly, there is strong resistance from areas which have been dropped from the priority list."

The policy committee also faces a dilemma over how much its new policy should be reflected in future plans, given the impending restructuring of the council in 2001. This will transfer the council to the Cabinet Office, as part of the government's plan to improve the country's administration.

At present, the Science Council relies heavily on STA's administration. The changes would give it its own staff, enabling it to act as an independent body to coordinate all government science and technology.

Some committee members feel that important policy decisions should be postponed until the new council, which will have more authority and an active role in policy making, is formed in two years' time. But others emphasize that the planned statement should be considered as a long-term strategy, saying that the basic policies are unlikely to change under the new council.

"If we are to make a clear statement of priorities in science and technology research, this should become a permanent feature in the policy, rather than a one-off event for the next fiscal year," said Hiroo Imura, former president of Kyoto University and chairman of the policy committee, at the committee's meeting last month.

But Imura admits that there is a limit to what can be decided under the domain of the existing council. "We hope that the new plan would at least be a step up from our previous policy," he says.

AsakoSaegusa

\section{and to use external scrutiny to increase competitiveness at universities}

[TOKYO] Japan's Science and Technology Council has called for significant changes in the way university research is carried out. In particular, it wants to create an independent body that would evaluate research externally so as to make it more competitive.

Such a body, according to an interim report on Japan's university research, is needed to compare the quality of research at national universities. The council's report, released at the end of last month, says the results of external evaluations should be reflected in the allocation of government research funds, particularly important given increasing budgetary pressures.

Also included in the report is a plan to create a system by which universities can claim for overheads on research grants.
This would allow researchers to use the grants to cover maintenance costs - which take up a substantial share of government research funds - as basic research funds, which are split equally among universities, decline.

The shift towards competitive and peer-reviewed grant schemes is in line with the government's efforts to make Japanese researchers internationally competitive. At present, according to the council, 88 per cent of Japanese universities, and all but one of its 98 national universities, carry out some form of research evaluation, but only a handful use external reviewers (see Nature 397, 378; 1999), most preferring a less stringent self-evaluation system.

Akito Arima, the education minister and director-general of the Science and Technology Agency, had promised to change the situation by setting up an independent body to assess national universities. His decision came in response to the government's proposal to turn national universities into semiautonomous institutions, a move strongly resisted both by universities and by the Ministry of Education, Science, Sports and Culture (Monbusho).

Many researchers support the idea of an external evaluation system, but some are concerned that Monbusho lacks the capacity and experience for this.

"The main concern is whether Monbusho's evaluation criteria would be suitable and relevant for the research fields concerned," says Robert Geller, associate professor in geophysics at Tokyo University. Geller was recently instrumental in setting up an external review system for reorganizing the university's four departments into a single department of Earth and planetary physics. The review, the fifth to be carried out at Tokyo University, was conducted by 11 external reviewers, five of whom were from outside Japan.

Geller admits that the review involved an "overwhelming amount of work". But he says it helped to identify the strengths and weaknesses of each faculty.

"I am hoping that Monbusho is prepared to create a research evaluation system that rates university departments in a given field on a common scale. If they fail to get it right, it would only be an additional burden to university researchers," he says. 